Research Article

\title{
Comparison of the Antioxidant Activities and Phenolic Content of Five Lonicera Flowers by HPLC-DAD/MS-DPPH and Chemometrics
}

\author{
Rong-rong Zhou, ${ }^{1}$ Xue-hui Liu, ${ }^{2}$ Lin Chen, ${ }^{2}$ Jian-hua Huang $\mathbb{D},{ }^{2}$ Xue-juan Liang, \\ Dan Wan, ${ }^{2}$ Shui-han Zhang, ${ }^{2}$ and Lu-qi Huang $\mathbb{D}^{1,3}$ \\ ${ }^{1}$ Changchun University of Chinese Medicine, College of Pharmacy, Changchun, China \\ ${ }^{2}$ Hunan Academy of Chinese Medicine, Research Institute of Chinese Medicine, Changsha, China \\ ${ }^{3}$ China Academy of Chinese Medical Sciences, National Resource Center for Chinese Materia Medica, Beijing, China
}

Correspondence should be addressed to Jian-hua Huang; huangjianhua1985@163.com and Lu-qi Huang; huangluqi01@126.com

Received 13 January 2020; Accepted 27 February 2020; Published 1 April 2020

Academic Editor: Barbara Bojko

Copyright (c) 2020 Rong-rong Zhou et al. This is an open access article distributed under the Creative Commons Attribution License, which permits unrestricted use, distribution, and reproduction in any medium, provided the original work is properly cited.

\begin{abstract}
The Lonicera plants (family Caprifoliaceae) with strong antioxidant activity are used as potential health-supporting phytochemicals. Studying the detailed relationships between bioactive compounds and their antioxidant activity is important for further comprehensive development and application of them. In this paper, the antioxidant capacities and compositions of five species of Lonicera flowers were investigated by using the online HPLC-DAD/MS-DPPH method. Results indicated that the samples contained higher amounts of phenols had better antioxidant activity. Furthermore, principal component analysis and linear regression were further used to analyze the correlations between antioxidant capacity and compounds and find the compounds having higher contribution to antioxidant activity. 5-O-Caffeoylquinic acid, 4-O-caffeoylshikimic acid, methyl-5-O-caffeoylquinate, 1,4-di-O-caffeoylquinic acid, and 3,4,5-tri-O-caffeoylquinic acid were screened as stronger antioxidant candidates. In this study, HPLC-DAD/MS and antioxidant activity methods were combined together to analyze the compounds' information and activity assays of Lonicera, which might provide more evidence for its quality control.
\end{abstract}

\section{Introduction}

Epidemiological studies strongly showed antioxidant protection effects against various diseases or illness relevant to oxidative stress, such as aging, cardiovascular diseases, cancer, stoke, diabetes, Alzheimer's disease, hypertension, and inflammation [1-5]. Various antioxidants from natural products are excellent candidates, e.g., phenolic acids, tannins, lignans, and flavonoids) [6-10]. Thus, searching antioxidants from natural products has attracted a lot of attention.

Lonicera is one of the most crucial genera in the Caprifoliaceae family [11-13]. In China, there are several Lonicera species which have been used as herbal to treat headache, pharyngodynia, acute fever, respiratory infection, epidemic disease, and pyocutaneous disease [14-18] for centuries. Recently, a lot of studies have disclosed the existence of phenolic acids, flavonoids, saponins, and iridoids in Lonicera species [19-23]. In the Chinese Pharmacopoeia (2015), four species, including L. hypoglauca, L. confusa, $L$. fulvotomentosa and L. macranthoides, were recorded as Flos Lonicerae (Shanyinhua in Chinese). Antioxidant activity was the shared pharmacological activity of Lonicera species.

Some studies were proposed to compare or discover these antioxidants, namely $\mathrm{Li}$ et al., found that Lonicera macranthoides presented better antioxidant activities than Lonicerae japonicae [24]. However, there is a lack of systematic investigations on the correlations between bioactive components and antioxidant capacity of Flos Lonicerae. Moreover, the antioxidative capacities of different varieties of Flos Lonicerae were usually affected by the contents of 
antioxidant compounds and their oxidation resistances. Analysis of antioxidant capacities of different varieties of Flos Lonicerae cannot be performed accurately by any single antioxidant compound. Accordingly, the content and oxidation resistance of different antioxidant components should be considered together to comprehensively evaluate the antioxidant activities of Flos Lonicerae.

Hyphenated techniques are needed for the analysis of these antioxidants from complex samples. "HPLC-DPPH method" is one of these kinds of hyphenated techniques and had been widely applied to identify antioxidants in a complex matrix, such as herbs and natural products [25-30]. In the current study, an online HPLC technique coupled with $\mathrm{MS}^{\mathrm{n}}$ and the DPPH-HPLC method was used to screen and characterize the antioxidants in Flos Lonicerae. Firstly, the antioxidant activities of five Lonicera flowers were estimated. Then, a DPPH-HPLC assay was used to screen the active compounds, and LC-MS/MS was further used to identify the active compounds. Furthermore, the correlations between bioactive compounds and their antioxidant capacity were also constructed by using a linear regression model.

\section{Experimental}

2.1. Apparatus. Agilent 6530 Accurate-Mass Q-TOF-LC/MS system coupled with a Quat-Pump was utilized in this study. An InertSustain-C18 (5-micron, $4.6 \times 250 \mathrm{~mm})$ column was used to separate the peaks in samples. The mobile phases A ( $0.1 \%$ formic acid in water) and B (acetonitrile) were programmed as follows: 0 5 min, 5\% B; 5 10 min, 5\% 23\% B; 10 15 min, 23\% B; 15 20 min, 23\% 36\% B; 20 25 min, 36\% B; $25 \sim 45 \mathrm{~min}, \quad 36 \% \sim 50 \%$ B; $45 \sim 55 \mathrm{~min}, 50 \% \sim 70 \%$ B; $55 \sim 60 \mathrm{~min}, 70 \% \sim 72 \% \mathrm{~B}$. The injection volume was $10 \mu \mathrm{L}$, and the flow rate was $1 \mathrm{~mL} / \mathrm{min}$ and column temperature was $28^{\circ} \mathrm{C}$. The LC-MS system was controlled by an Agilent ChemStation to record total ion chromatograms and mass spectra, with following conditions: dry gas: $\mathrm{N} 2,8.0 \mathrm{~L} / \mathrm{min}$, $322^{\circ} \mathrm{C}$; sheath gas: $\mathrm{N} 2,11 \mathrm{~L} / \mathrm{min}, 322^{\circ} \mathrm{C}$; fragmentor voltage, $180 \mathrm{~V}$; capillary voltage, $3500 \mathrm{~V}$ ).

2.2. Reagents. DPPH was purchased from Sigma-Aldrich (Steinheim, Germany). Analytical grade ethanol, methanol, and formic acid were purchased from Sinopharm Chemical Reagent Co., Ltd (China). The chromatographic grade of acetonitrile was purchased from Merk (Germany). Ultrapure water was purified and filtered by a Milli-Q water system (Millipore, Bedford, MA, USA).

2.3. Preparation of Lonicera. Thirty batches of flower buds of Lonicera species (6 batches of each species) were collected from cultivated markets in China. The species of all samples were authenticated by Prof. Zhao-ming Xie (Research Institute of Chinese Medicine, Hunan Academy of Chinese Medicine, Changsha, Hunan). All samples were powdered and screened through 80 mesh sieves. $3.0 \mathrm{~g}$ prepared powder of each sample was accurately weighed, mixed with $30 \mathrm{~mL}$ of $80 \%$ ethanol, and then extracted by ultrasonic extraction for $40 \mathrm{~min}$. After adjustment to the initial weight by ethanol, the supernatant was collected and filtered through a $0.45 \mu \mathrm{m}$ membrane filter before using for HPLC analysis.

2.4. DPPH Assay for Evaluation of Antioxidant Activity. Analysis of antioxidant activity was followed by a previous method with brief improvement [31]. The DPPH. solution was used as the control. The ability to scavenge DPPH. was calculated according to the following equation: $\left[\left(A_{\text {control }}-A_{\text {sample }}\right) / A_{\text {control }}\right] \times 100 \% . \mathrm{IC}_{50}(50 \%$ inhibition $)$ was calculated based on the graph plotting inhibition percentage. The above experiment results were expressed as the mean \pm standard deviation (SD), parallel tested three times.

2.5. HPLC-DAD/MS-DPPH Assay. Prepared samples' extract $(300 \mu \mathrm{L})$ was mixed with methanol to $1.5 \mathrm{~mL}$ and then reacted with $\mathrm{DPPH} \cdot(300 \mu \mathrm{L}, 30 \mathrm{mg} / \mathrm{mL})$ at $38^{\circ} \mathrm{C}$ for $40 \mathrm{~min}$. Then, each sample was passed through a $0.22 \mu \mathrm{m}$ filter before HPLC-DAD/MS analysis. Sample $1.5 \mathrm{~mL}$ without DPPH. was used as the control. MS data were acquired across the range $m / z 50-1000$ in negative ion modes with an acquisition rate of 1.02 spectra/s, by the Agilent 6530 AccurateMass QTOF/MS system with an ESI interface.

2.6. Statistical Analysis. Averaged result of three replicates for each sample was used for the subsequent statistical analysis. The principal component analysis (PCA) method was used to transform the original measured variables into new uncorrelated variables (principal components) and to display the relationship among samples or different species. Also, the linear regression model was proposed by using the software Matlab.

\section{Results and Discussion}

3.1. Antioxidant Activity of Five Lonicera Flowers. The antioxidant activities of these five species are shown in Table 1. The species L. macranthoides showed excellent capacity to scavenge the DPPH radical with the $\mathrm{IC}_{50}$ value of $235.27 \mu \mathrm{g} /$ $\mathrm{ml}$ (Table 1). The results indicated that L. macranthoides flowers have strong antioxidant activity. Therefore, HPLCDAD/MS-DPPH was further applied to screen and characterize contained antioxidants.

3.2. Screening and Analyzing Antioxidants by HPLC-DAD/ $M S-D P P H$. HPLC-DAD/MS-DPPH was a rapid method and can screen antioxidants from complex mixtures without complicated sample pretreatment. It was believed that the peak areas of these antioxidants in the HPLC chromatogram will be decreased if they react with DPPH $\bullet$. Figure 1 shows the results of Lonicera japonica before and after reaction with DPPH•. It can be found that the peak areas of compounds 1 to compound 15 were obviously decreased after reacting with the DPPH• solution. Therefore, these compounds (compound 1 to compound 15) were considered to have antioxidant properties.

Then, both positive and negative ion modes were determined to obtain the appropriate ionization of these compounds. Peak identification was assigned primarily by 
TABLe 1: Antioxidant activities of five Lonicera flowers in the DPPH assay.

\begin{tabular}{lr}
\hline Samples & $\mathrm{DPPH}\left(\mathrm{IC} \mathrm{F}_{50}, \mu \mathrm{g} / \mathrm{ml}\right)$ \\
\hline Lonicera macranthoides Hand.-Mazz. & $235.27 \pm 1.21^{*}$ \\
Lonicera fulvotomentosa Hsu et S. C. Cheng & $284.87 \pm 1.05^{*}$ \\
Lonicera japonica Thunb. & $464.48 \pm 1.32$ \\
Lonicera hypoglauca Miq. & $580.96 \pm 0.95$ \\
Lonicera confusa (Sweet) DC. & $905.23 \pm 1.02$ \\
\hline
\end{tabular}

Each value is mean $\pm \mathrm{SD}(n=3)$.

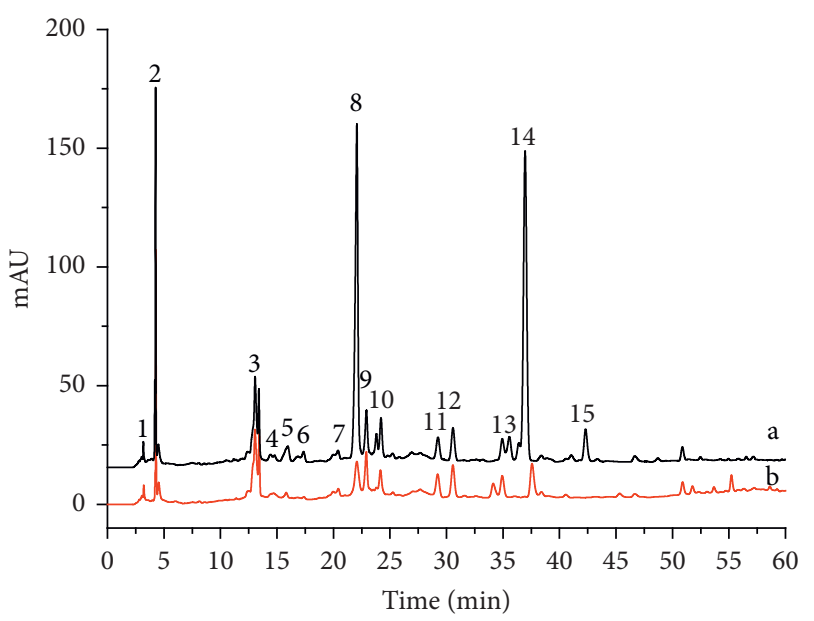

Figure 1: HPLC (a) and HPLC-DPPH (b) of Lonicera japonica monitored by HPLC-DAD-QTOF-MS/MS in the negative ion mode.

means of the fragment ions and corresponding $\mathrm{MS}^{2}$ fragment ions. The collision energy for $\mathrm{MS}^{2}$ experiments was optimized in the range from 15 to $60 \mathrm{eV}$, and the best results for structure identification were obtained at $35 \mathrm{eV}$.

Caffeoylquinic acids were reported as main metabolites in Lonicera species in previous studies, and their accurate identification was a very difficult task due to their similar regional and geometrical isomerism. The distinct MS/MS fragmentation pathways and elution order could be used to assist in the structure identification (Table 2). Four compounds (1-4) were pairs of isomers with molecular weight at $m / z$ value of about $353.08\left(\mathrm{C}_{16} \mathrm{H}_{18} \mathrm{O}_{9}\right)$. By analysis of the MS/ MS spectra and comparison with standards, 1, 2 and 3 were confirmed as 3-O-caffeoylquinic acid, 5-O-caffeoylquinic acid, and 4-O-caffeoylquinic acid. Then, we speculated that compound 4 could be cis-4-O-caffeoylquinic acid. It has been reported that caffeoylquinic acid derivatives underwent trans-cis isomerization after being exposed to UV, and cis caffeoylquinic acids had been found in the natural resource. Then, we radiated 4-O-caffeoylquinic acid with UV light at $254 \mathrm{~nm}$ for $65 \mathrm{~min}$, using a similar approach and by comparison with standards, compounds $11-15$ were assigned as 3,4-di-O-caffeoylquinic acid, 3,5-di-O-caffeoylquinicacid, 4,5-di-O-caffeoylquinic acid, 1,4-di-O-caffeoylquinic acid, and 3,4,5-tri-O-caffeoylquinic acid, respectively. Thus, combination of HPLC-DAD/MS techniques with DPPHHPLC to detect antioxidant compounds has the advantages of that chromatography as the separation method, an ESIMS/MS as the identification method, and a DPPH assay as the activity evaluation method.
3.3. Principal Component Analysis of Compound Content and Antioxidant Activity. PCA could convert variables into a few comprehensive principal components to exhibit the relationships of data. The peak areas of these 16 compounds selected by HPLC-DAD/MS and DPPH-HPLC were imputed to PCA for data analysis. The first two principal components (PC1 and PC2) were found and accounted for approximately $81.7 \%$ of total variances, indicating that PC1 and PC2 contained most information of all variables. Generally, the score plot could discriminate differences in samples as similar or nonsimilar. As shown in Figure 2, $L$. japonica, L. macranthoides, L. fulvotomentosa, L. confuse, and L. hypoglauca could be clearly discriminated from each other. The loading values for these compounds could be used to estimate the importance or contributions to the classification. As can be seen from Figure 2, five compounds, com $2,3,8,14$, and 15, had the higher loading values in the classification of different species.

Furthermore, a linear regression model was carried out to identify relationships between these five compounds and the samples' antioxidant activity in Flos Lonicerae. In the linear regression model establish process, the peak areas of these five selected compounds were used as the independent variables $(x)$, and the $\mathrm{IC}_{50}$ values obtained by the $\mathrm{DPPH}$. assay method were used as the dependent variables $(y)$. A linear regression model was established based on the independent variables $(x)$ and the dependent variables $(y)$. The linear model is listed in Figure 3. Adjusted data points are computed by adding the residual to the adjusted fitted value for each observation. Two indexes, $R$-squared and adjusted 
TABLE 2: ESI-MS² results of antioxidants in Lonicera.

\begin{tabular}{|c|c|c|c|c|c|c|c|}
\hline No. & $\mathrm{tR} / \mathrm{min}$ & {$[\mathrm{M}-\mathrm{H}]-(m / z)$} & $\begin{array}{l}\text { Exptl. exact } \\
\text { mass }\end{array}$ & Fragment ions $(\mathrm{m} / z)$ & $\begin{array}{l}\text { Error } \\
(\mathrm{ppm})\end{array}$ & $\begin{array}{l}\text { Molecular } \\
\text { formula }\end{array}$ & Identification \\
\hline 1 & 4.281 & {$[\mathrm{M}-\mathrm{H}]-$} & 353.0877 & $191.0559,179.0343$ & 0.53 & $\mathrm{C} 16 \mathrm{H} 18 \mathrm{O} 9$ & 3-O-Caffeoylquinic acid \\
\hline 2 & 15.983 & {$[\mathrm{M}-\mathrm{H}]-$} & 353.0875 & 191.0557 & -2.57 & $\mathrm{C} 16 \mathrm{H} 18 \mathrm{O} 9$ & 5-O-Caffeoylquinic acid \\
\hline 3 & 19.586 & {$[\mathrm{M}-\mathrm{H}]-$} & 335.0773 & $\begin{array}{l}179.0346,161.0242, \\
135.0446,317.0667\end{array}$ & 0.82 & $\mathrm{C} 16 \mathrm{H} 18 \mathrm{O} 9$ & $\begin{array}{c}\text { 4-O-Caffeoylshikimic } \\
\text { acid }\end{array}$ \\
\hline 4 & 19.754 & {$[\mathrm{M}-\mathrm{H}]-$} & 353.0877 & $173.0453,179.0345,191.0558$ & 0.45 & $\mathrm{C} 16 \mathrm{H} 18 \mathrm{O} 9$ & $\begin{array}{l}\text { cis-4-O-Caffeoylquinic } \\
\text { acid }\end{array}$ \\
\hline 5 & 19.987 & {$[\mathrm{M}-\mathrm{H}]-$} & 367.1026 & $161.0244,135.0452$ & 2.37 & $\mathrm{C} 17 \mathrm{H} 20 \mathrm{O} 9$ & $\begin{array}{l}\text { Methyl-4-O- } \\
\text { caffeoylquinate }\end{array}$ \\
\hline 6 & 21.271 & {$[\mathrm{M}-\mathrm{H}]-$} & 404.3684 & $371.0243,179.0455$ & -2.15 & $\mathrm{C} 17 \mathrm{H} 24 \mathrm{O} 11$ & Secoxyloganin \\
\hline 7 & 21.623 & {$[\mathrm{M}-\mathrm{H}]-$} & 335.0775 & $179.0344,135.0451$ & 1.85 & $\mathrm{C} 16 \mathrm{H} 16 \mathrm{O} 8$ & $\begin{array}{c}\text { 3-O-Caffeoylshikimic } \\
\text { acid }\end{array}$ \\
\hline 8 & 23.290 & {$[\mathrm{M}-\mathrm{H}]-$} & 367.1026 & $\begin{array}{c}179.0345,135.0452 \\
191.0559,161.0243\end{array}$ & 0.64 & $\mathrm{C} 17 \mathrm{H} 20 \mathrm{O} 9$ & $\begin{array}{l}\text { Methyl-5-O- } \\
\text { caffeoylquinate }\end{array}$ \\
\hline 9 & 27.345 & {$[\mathrm{M}-\mathrm{H}]-$} & 381.1084 & $161.0243,135.0452$ & -2.35 & $\mathrm{C} 18 \mathrm{H} 22 \mathrm{O} 9$ & $\begin{array}{c}\text { Ethyl-4-O- } \\
\text { caffeoylquinate }\end{array}$ \\
\hline 10 & 30.296 & {$[\mathrm{M}-\mathrm{H}]-$} & 381.1081 & $\begin{array}{c}179.0343,135.0454 \\
191.0558,161.0245\end{array}$ & -2.17 & $\mathrm{C} 18 \mathrm{H} 22 \mathrm{O} 9$ & $\begin{array}{c}\text { Ethyl-5-O- } \\
\text { caffeoylquinate }\end{array}$ \\
\hline 11 & 33.269 & {$[\mathrm{M}-\mathrm{H}]-$} & 515.1193 & $\begin{array}{l}353.0876,173.0453 \\
179.03445,191.0559\end{array}$ & -0.82 & $\mathrm{C} 25 \mathrm{H} 23 \mathrm{O} 12$ & $\begin{array}{l}\text { 3,4-di-O-Caffeoylquinic } \\
\text { acid }\end{array}$ \\
\hline 12 & 35.504 & {$[\mathrm{M}-\mathrm{H}]-$} & 515.1196 & $353.0876,191.0558,179.0345$ & 0.69 & $\mathrm{C} 25 \mathrm{H} 23 \mathrm{O} 12$ & $\begin{array}{c}\text { 3,5-di-O-Caffeoylquinic } \\
\text { acid }\end{array}$ \\
\hline 13 & 37.875 & {$[\mathrm{M}-\mathrm{H}]-$} & 515.1195 & $\begin{array}{l}353.0874,173.0452 \\
179.0345,191.0559\end{array}$ & -3.12 & $\mathrm{C} 25 \mathrm{H} 23 \mathrm{O} 12$ & $\begin{array}{l}\text { 4,5-di-O-Caffeoylquinic } \\
\text { acid }\end{array}$ \\
\hline 14 & 42.663 & {$[\mathrm{M}-\mathrm{H}]-$} & 515.1197 & $\begin{array}{c}353.0876,173.0453 \\
191.0562,179.0347\end{array}$ & -2.53 & $\mathrm{C} 25 \mathrm{H} 23 \mathrm{O} 12$ & $\begin{array}{l}\text { 1,4-di-O-Caffeoylquinic } \\
\text { acid }\end{array}$ \\
\hline 15 & 43.397 & {$[\mathrm{M}-\mathrm{H}]-$} & 677.1592 & $515.1193,353.0876$ & -0.49 & С34H30O15 & $\begin{array}{c}\text { 3,4,5-tri-O- } \\
\text { Caffeoylquinic acid }\end{array}$ \\
\hline
\end{tabular}

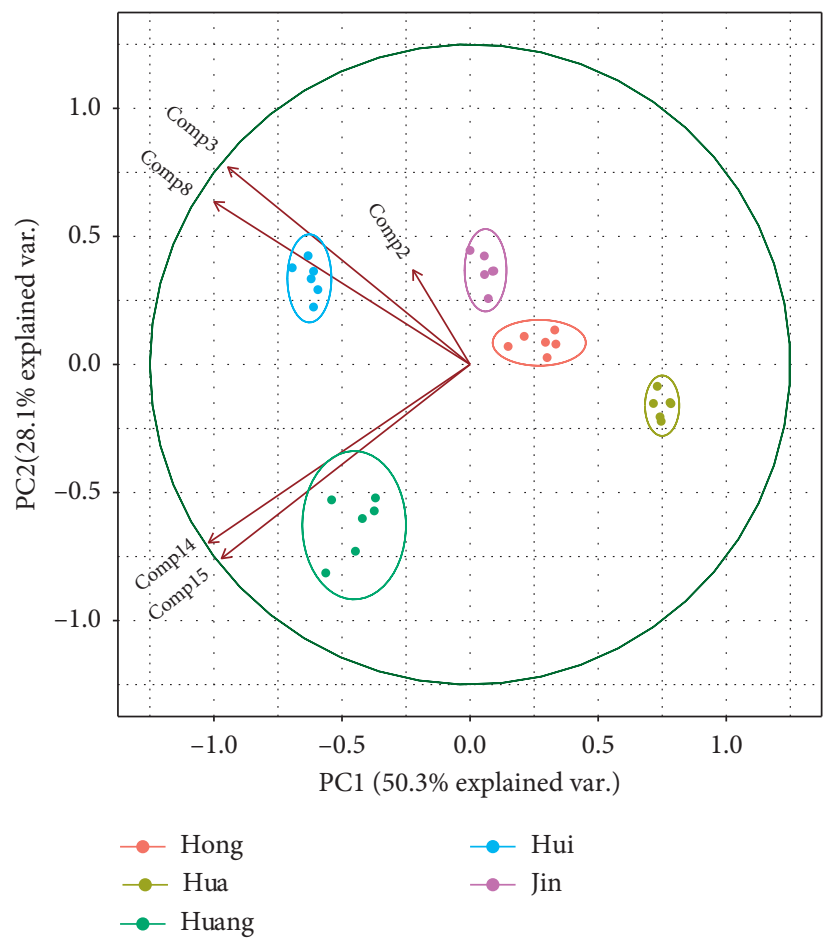

Figure 2: Score and loading plot from the PCA of main antioxidant compounds. 


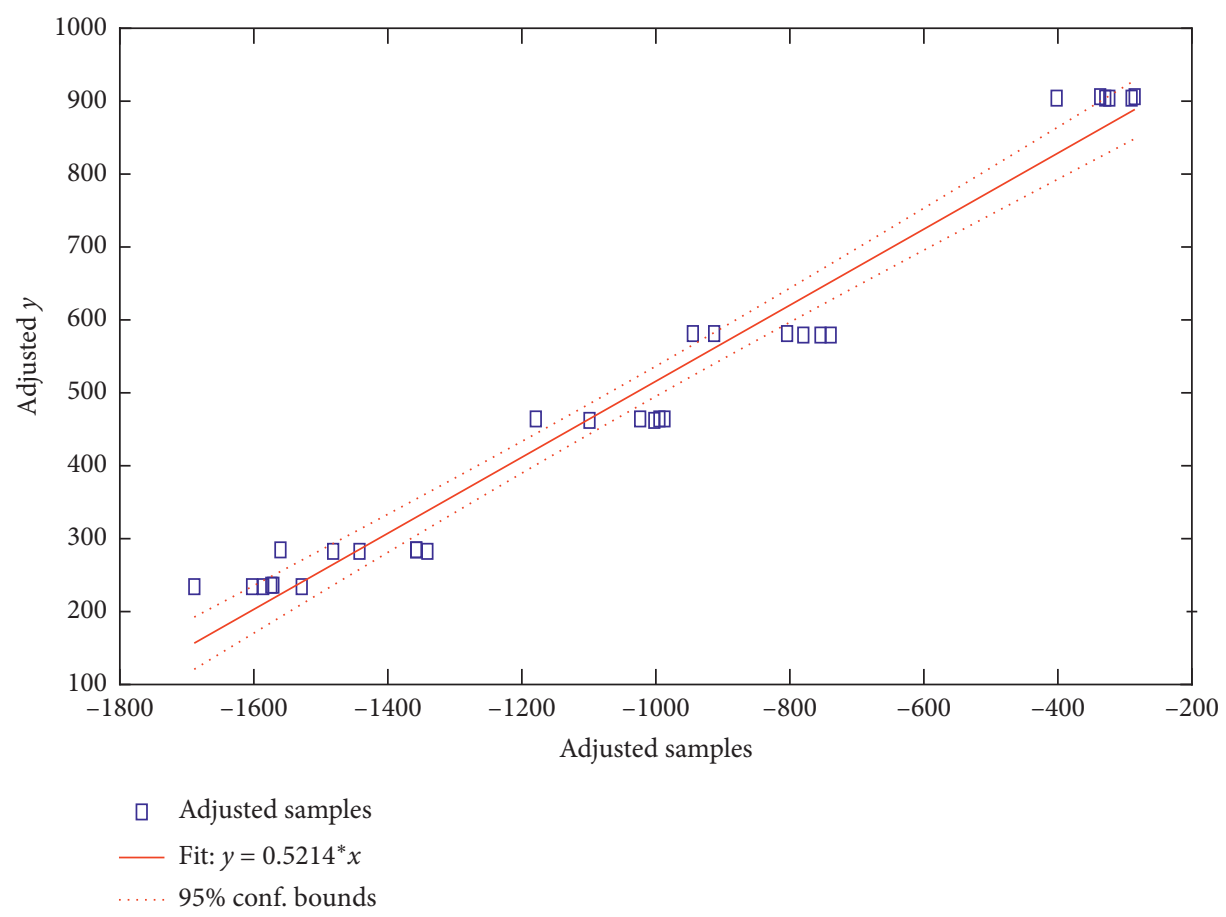

FIgURE 3: The fitted model based on selected five compounds and antioxidant activity.

$R$-squared, were calculated to estimate the linear regression model. In the current study, the peak areas of com 2, 3, 8, 14, and 15 were fitted with their antioxidant activities. The $R$ squared and adjusted $R$-squared values were 0.966 and 0.959 , respectively. These results showed that these five compounds are in strong relation with their antioxidant activities.

\section{Conclusions}

In this paper, the antioxidant assays demonstrated that all the samples exerted perfect antioxidant capacity in the following order: Lonicera macranthoides $>$ Lonicera fulvotomentosa > Lonicera japonica Thunb > Lonicera hypoglauca Miq > Lonicera confusa. In addition, the results from PCA and DPPH-spiking HPLC analysis confirmed that 5-Ocaffeoylquinic acid, 4-O-caffeoylshikimic acid, methyl-5-Ocaffeoylquinate, 1,4-di-O-caffeoylquinic acid, and 3,4,5-tri$\mathrm{O}$-caffeoylquinic acid contributed to antioxidant activity. Therefore, the HPLC-DAD/MS-DPPH analysis method is expected to provide efficient, time-saving, and sensitive technology for screening and identification of radical scavengers from a complex matrix, which will benefit for the further utilization of Flos Lonicerae.

\section{Data Availability}

The data used to support the findings of this study are available from the corresponding author upon request.

\section{Conflicts of Interest}

The authors confirm that this article content has no conflicts of interest.

\section{Authors' Contributions}

Rong-rong Zhou and Xue-hui Liu contributed equally to this article.

\section{Acknowledgments}

This work was supported by the Natural Science Foundation of China (nos. 81603400 and. 81673585), Training Program for Excellent Young Innovators of Changsha (kq1802017), Key Research and Development Project of Hunan Province Science and Technology (nos. 2019XF5064 and 2019XF5062), Key Research and Development Project of Changsha Province Science and Technology (kq1901067), National Standard Project of Chinese Medicine (ZYBZH-YHUN-21), Scientific Research of Hunan Province of Chinese Medicine (no. 201702), Program of Survey and Monitoring of Chinese Medicines for National Drugs ([2013]135), Construction Project of Quality Monitoring System of Raw Materials of Chinese Medicine (no. [2014]76), Construction Project of Seedling Base of Rare Chinese Medicinal and Processing Technology of Chinese Medicinal Materials ([2015]78), and Program of Survey of Chinese Medicines of China ([2017]66).

\section{References}

[1] X.-L. Jiang, L. Wang, E.-J. Wang et al., "Flavonoid glycosides and alkaloids from the embryos of Nelumbo nucifera seeds and their antioxidant activity," Fitoterapia, vol. 125, pp. 184-190, 2018.

[2] M. Grzesik, K. Naparło, G. Bartosz, and I. Sadowska-Bartosz, "Antioxidant properties of catechins: comparison with other antioxidants," Food Chemistry, vol. 241, pp. 480-492, 2018. 
[3] M. Çol Ayvaz, B. Ömür, Ö. Ertürk, and D. Kabakçi, "Phenolic profiles, antioxidant, antimicrobial, and DNA damage inhibitory activities of chestnut honeys from Black Sea region of Turkey," Journal of Food Biochemistry, vol. 42, Article ID e12502, 2018.

[4] S. Hwang, J. K. Kim, I. H. Kim, and Y. H. Lim, "Inhibitory effect of ethanolic extract of Ramulus mori on adipogenic differentiation of 3T3-L1 cells and their antioxidant activity," Journal of Food Biochemistry, vol. 42, Article ID e12469, 2018.

[5] T. Singh, S. C. Bhutia, M. L. Sherpa, and S. Dewan, "Correlation of cartilage metabolic markers \& antioxidants with the severity of knee osteoarthritis," The Indian Journal of Medical Research, vol. 144, p. 932, 2016.

[6] H. Parhiz, A. Roohbakhsh, F. Soltani, R. Rezaee, and M. Iranshahi, "Antioxidant and anti-inflammatory properties of the citrus flavonoids hesperidin and hesperetin: an updated review of their molecular mechanisms and experimental models," Phytotherapy Research, vol. 29, no. 3, pp. 323-331, 2015.

[7] D. L. McKay, C.-Y. O. Chen, C. A. Zampariello, and J. B. Blumberg, "Flavonoids and phenolic acids from cranberry juice are bioavailable and bioactive in healthy older adults," Food Chemistry, vol. 168, pp. 233-240, 2015.

[8] M. Bai, S. F. Li, S. F. Liu, X. B. Wang, X. X. Huang, and S. J. Song, "Iridoid glycoside and lignans from a wild vegetable (Patrinia villosa Juss.) with antioxidant activity," Journal of Food Biochemistry, vol. 42, Article ID e12521, 2018.

[9] M. C. Figueroa-Espinoza, A. Zafimahova, P. G. M. Alvarado, E. Dubreucq, and C. Poncet-Legrand, "Grape seed and apple tannins: emulsifying and antioxidant properties," Food Chemistry, vol. 178, pp. 38-44, 2015.

[10] A. Y. Yashin, D. B. Yashunskii, A. N. Vedenin, N. E. Nifant'ev, B. V. Nemzer, and Y. I. Yashin, "Chromatographic determination of lignans (antioxidants) in food products," Journal of Analytical Chemistry, vol. 73, no. 5, pp. 399-406, 2018.

[11] L. Ardó, G. Yin, P. Xu et al., "Chinese herbs (Astragalus membranaceus and Lonicera japonica) and boron enhance the non-specific immune response of Nile tilapia (Oreochromis niloticus) and resistance against Aeromonas hydrophila," Aquaculture, vol. 275, no. 1-4, pp. 26-33, 2008.

[12] X. Shang, H. Pan, M. Li, X. Miao, and H. Ding, "Lonicera japonica thunb.: ethnopharmacology, phytochemistry and pharmacology of an important traditional Chinese medicine," Journal of Ethnopharmacology, vol. 138, no. 1, pp. 1-21, 2011.

[13] L.-Y. Peng, S.-X. Mei, B. Jiang, H. Zhou, and H.-D. Sun, "Constituents from Lonicera japonica," Fitoterapia, vol. 71, no. 6, pp. 713-715, 2000.

[14] P. J. Houghton, Z. Boxu, and Z. Xisheng, "A clinical evaluation of the Chinese herbal mixture "Aden-I" for treating respiratory infections," Phytotherapy Research, vol. 7, no. 5, pp. 384-386, 1993.

[15] S. J. Lee, K. H. Son, H. W. Chang, S. S. Kang, and H. P. Kim, "Antiinflammatory activity of Lonicera japonica," Phytotherapy Research, vol. 12, no. 6, pp. 445-447, 1998.

[16] X.-H. Jin, K. Ohgami, K. Shiratori et al., "Effects of blue honeysuckle (Lonicera caerulea L.) extract on lipopolysaccharide-induced inflammation in vitro and in vivo," Experimental Eye Research, vol. 82, no. 5, pp. 860-867, 2006.

[17] E. J. Lee, J. S. Kim, H. P. Kim, J.-H. Lee, and S. S. Kang, "Phenolic constituents from the flower buds of Lonicera japonica and their 5-lipoxygenase inhibitory activities," Food Chemistry, vol. 120, no. 1, pp. 134-139, 2010.

[18] W. J. Kwak, C. K. Han, H. W. Chang, H. P. Kim, S. S. Kang, and K. H. Son, "Loniceroside C, an anti-inflammatory saponin from Lonicera japonica," Chemical \& Pharmaceutical Bulletin, vol. 51, no. 3, pp. 333-335, 2003.

[19] J. Yong, X. Wu, and C. Lu, "Chemical constituents isolated from the fruits of Lonicera maackii," Chemistry of Natural Compounds, vol. 50, no. 4, pp. 765-766, 2014.

[20] Y. Chen, X. Feng, X. Jia, M. Wang, J. Liang, and Y. Dong, "Triterpene glycosides from Lonicera. Isolation and structural determination of seven glycosides from flower buds of Lonicera macranthoides," Chemistry of Natural Compounds, vol. 44, no. 1, pp. 39-43, 2008.

[21] Y. Peng, F. Liu, and J. Ye, "Determination of phenolic acids and flavones inLonicera japonica thumb. by capillary electrophoresis with electrochemical detection," Electroanalysis, vol. 17, no. 4, pp. 356-362, 2005.

[22] Y. Song, S.-L. Li, M.-H. Wu, H.-J. Li, and P. Li, "Qualitative and quantitative analysis of iridoid glycosides in the flower buds of Lonicera species by capillary high performance liquid chromatography coupled with mass spectrometric detector," Analytica Chimica Acta, vol. 564, no. 2, pp. 211-218, 2006.

[23] I. Souzu and H. Mitsuhashi, "Structures of iridoids from lonicera morrowii a. gray," Tetrahedron Letters, vol. 10, no. 32, pp. 2725-2728, 1969.

[24] N. Dung, V. Bajpai, A. Rahman, J. Yoon, and S. Kang, "Phenolic contents, antioxidant and tyrosinase inhibitory activities of Lonicera japonica Thumb," Journal of Food Biochemistry, vol. 35, no. 1, pp. 148-160, 2010.

[25] X. Dai, Q. Huang, B. Zhou, Z. Gong, Z. Liu, and S. Shi, "Preparative isolation and purification of seven main antioxidants from Eucommia ulmoides Oliv. (Du-Zhong) leaves using HSCCC guided by DPPH-HPLC experiment," Food Chemistry, vol. 139, no. 1-4, pp. 563-570, 2013.

[26] E. Riethmüller, Á Könczöl, D. Szakál, K. Végh, G. T. Balogh, and Á Kéry, "HPLC-DPPH screening method for evaluation of antioxidant compounds in Corylus species," Natural Product Communications, vol. 11, no. 5, p. 1934578X1601100, 2016.

[27] J. Dang, L. Zhang, Y. Shao et al., "Preparative isolation of antioxidative compounds from Dracocephalum heterophyllum using off-line two-dimensional reversed-phase liquid chromatography/hydrophilic interaction chromatography guided by on-line HPLC-DPPH assay," Journal of Chromatography B, vol. 1095, pp. 267-274, 2018.

[28] V. Pedan, N. Fischer, K. Bernath, T. Hühn, and S. Rohn, "Determination of oligomeric proanthocyanidins and their antioxidant capacity from different chocolate manufacturing stages using the NP-HPLC-online-DPPH methodology," Food Chemistry, vol. 214, pp. 523-532, 2017.

[29] M. Liu, X. Li, Q. Liu, S. Xie, F. Zhu, and X. Chen, "Preparative isolation and purification of 12 main antioxidants from the roots of Polygonum multiflorum Thunb using high-speed countercurrent chromatography and preparative HPLC guided by $1,1^{\prime}$-diphenyl-2-picrylhydrazyl-HPLC," Journal of Separation Science.

[30] W. Wang, L. Jiao, Y. Tao et al., "On-line HPLC-DPPH bioactivity-guided assay for isolated of antioxidative phenylpropanoids from Qinghai-Tibet Plateau medicinal plant Lancea tibetica," Journal of Chromatography B, vol. 11061107, pp. 1-10, 2019.

[31] P. Wang, J.-H. Yu, K. Zhu et al., "Phenolic bisabolane sesquiterpenoids from a Thai mangrove endophytic fungus, Aspergillus sp. xy02," Fitoterapia, vol. 127, pp. 322-327, 2018. 